This document was prepared in conjunction with work accomplished under Contract No. DE-AC09-96SR18500 with the U. S. Department of Energy.

\title{
DISCLAIMER
}

This report was prepared as an account of work sponsored by an agency of the United States Government. Neither the United States Government nor any agency thereof, nor any of their employees, nor any of their contractors, subcontractors or their employees, makes any warranty, express or implied, or assumes any legal liability or responsibility for the accuracy, completeness, or any third party's use or the results of such use of any information, apparatus, product, or process disclosed, or represents that its use would not infringe privately owned rights. Reference herein to any specific commercial product, process, or service by trade name, trademark, manufacturer, or otherwise, does not necessarily constitute or imply its endorsement, recommendation, or favoring by the United States Government or any agency thereof or its contractors or subcontractors. The views and opinions of authors expressed herein do not necessarily state or reflect those of the United States Government or any agency thereof. 


\section{Kinetics and Equilibrium Sorption Models: Fitting Plutonium, Strontium, Uranium and Neptunium Loading on Monosodium Titanate (MST)}

by

FERNANDO FONDEUR

Westinghouse Savannah River Company

Savannah River Site

Aiken, South Carolina 29808

Additional Authors:

This paper was prepared in connection with work done under the above contract number with the U. S. Department of Energy. By acceptance of this paper, the publisher and/or recipient acknowledges the U. S. Government's right to retain a nonexclusive, royalty-free license in and to any copyright covering this paper, along with the right to reproduce and to authorize others to reproduce all or part of the copyrighted paper. 
Kinetics and Equilibrium Sorption Models: Fitting Plutonium, Strontium, Uranium and Neptunium Loading on Monosodium Titanate (MST)

\author{
F. F. Fondeur, D. T. Hobbs, M. J. Barnes, T. B. Peters and S. D. Fink
}

Westinghouse Savannah River Company

Aiken, South Carolina 29808 


\begin{abstract}
The Dubinin-Astashov (DA) isotherm parameters for $\mathrm{U}, \mathrm{Pu}, \mathrm{Sr}$ and $\mathrm{Np}$ have been updated to include additional data obtained since the original derivation. The DA isotherms were modified to include a kinetic function derived by Rahn to describe sorbate loading from the beginning of sorption up to steady state. The final functions describe both kinetic and thermodynamic sorption.
\end{abstract}

\title{
INTRODUCTION
}

The Salt Waste Processing Facility (SWPF) and the Actinide Removal Process (ARP) will treat salt solution from the Tank Farm that contains actinide levels in excess of the Saltstone Waste Acceptance Criteria (WAC). Saltstone is the name given to the mixture of salts (from the supernate) and grout (cement). The SWPF is a future facility where cesium will be removed from the supernate (salt solution). The ARP is a future facility where strontium, plutonium, uranium, and neptunium will be removed to an acceptable concentration level for mixing with grout. The grout will be poured into vaults to be built below the ground. The supernate treatment includes removal of ${ }^{90} \mathrm{Sr}$ and alpha-emitting $\left({ }^{238,239,240} \mathrm{Pu},{ }^{237} \mathrm{~Np}\right)$ radionuclides from salt solution. The baseline technology features contacting the liquid waste with a sorbent (monosodium titanate (MST)) in a tank (batch mode). The rate and extent of Pu removal by MST sets the SWPF footprint and establishes cycle time and throughput for the ARP. To increase throughput and optimize the process, a predictive tool for actinide removal with MST is required. To this end, a 
previous study fitted several isotherm functions to existing actinide on MST sorption data (1). That study identified the Dubinin-Astashov (DA) function fitted the sorption data well.

Since the completion of that work, new actinide adsorption data has been collected $(2,3)$. This paper incorporates the new data with the previous databank and recalculates the Dubinin-Astashov parameters. In addition, this paper develops a predictive tool for estimating actinide removal from liquid waste as a function of time. The final equation predicts both actinide concentration as a function of time and equilibrium (steady state) concentrations.

\subsection{Experimental}

We recently conducted additional MST sorption tests to generate 44 data points. The new tests covered concentration ranges not previously studied. This data was checked for mass balance consistency (what is on the MST and remains in solution must equals the initial starting amount of radionuclide). The data was further checked for sorption competition (for example if variations in the concentration of one radionuclide affect the sorption of others). We performed correlation tests between the equilibrium sorption of a radionuclide on MST and the concentration of the remaining radionuclides. A negative correlation result is evidence of lack of sorption competition. This implies that the $\mathrm{Sr}$ and actinides are sorbing on different sites in MST. This allows fitting sorption data with functions that only include the radionuclide being studied without considering the 
presence of the other radionuclides. The shape of the curve, representing the amount of actinide loaded on MST and the remaining concentration of actinide in solution, is initially linear and then it reaches a steady state value as a function of actinide concentration in solution.

The equilibrium sorption data was re-fitted with a DA function. The fitting procedure included a non-linear square fitting (minimizing the Sum of Square Errors) that used the Newton-Ralphson searching criteria. Convergence was reached when either the objective (the sum of the square difference between the prediction from the Dubinin-Astashov function and the sorption data), or parameters changes or the gradient of change was less than $10^{-6}$. A similar criterion was used for fitting the kinetic sorption data to different kinetic functions.

To predict the amount of MST per unit volume of supernate (per liter) needed for a given DF value, we combined the Dubinin-Astashov equation with the mass balance equation. The Dubinin-Astashov equation follows $(4,5)$.

$q_{\text {equilibrim }}=q_{\text {equilibrim }}^{\text {maximum }} \times e^{-\left(\frac{R T}{E} \operatorname{Ln}\left(\frac{S}{\text { actiniddequilibrim }_{\text {en }}}\right)\right)^{n}}$

In this expression, $q_{\max }$ is the maximum strontium or actinide loaded on MST (given in $\mu$ mole/g), $E$ is the adsorption energy and $S$ is the maximum radionuclide concentration in 
solution tested. We coupled equation (1) to the mass balance equation between actinide in solution, on MST and the original concentration to generate equation 2.

$$
q_{\text {equilibrime }}=\frac{[\text { sorbate }]_{\text {initial }}}{[M S T]} \times\left(1-\frac{1}{D F}\right)
$$

In this expression, $[\text { sorbate }]_{\text {initial }}$ stands for the initial actinide concentration with $\mu$ molar units (before MST addition), [MST] is MST concentration in grams/L and $D F$ stands for decontamination factor. Combining equations (1) and (2) leads to the following expression.

$$
[M S T]=\frac{\left[\text { sorbate }_{\text {initial }}\right.}{q_{\text {equilibrim }}} \times\left[1-\frac{1}{D F_{\text {equilibrium }}}\right] \times e^{\left.a \times\left[n\left(\frac{S \times D F_{\text {equilibirim }}}{\text { Isorbate }}\right]_{\text {inital }}\right)\right]^{b}}
$$

From equation (3) given an initial sorbate concentration and desired decontamination factor, the MST concentration (grams/L) is easily obtained. Conversely, given an initial concentration of sorbate and MST concentration, the equation also provides the resulting decontamination factor.

To predict the "DF" value as a function of time, we rearranged the mass balance equation in terms of the equilibrium DF and sorbate loadings at equilibrium and time " $t$ " as shown in equation 4. 


$$
D F(t)=\frac{1}{1-\left(1-\frac{1}{D F_{\text {equilibriu } m}}\right) \times \frac{q(t)}{q_{\text {equilibriu } m}}}
$$

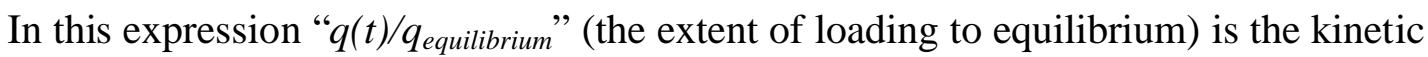
function describing how much sorbate loads on MST as a function time. One of the purposes of this work is to find a kinetic adsorption function for actinide sorption on MST that can be inserted in equation (4). A literature search identified several kinetic functions for adsorption process. Table 1 provides a list of the functions evaluated in this report. Table 2 provides the kinetic expressions for each of the functions listed in Table 1. For example, inserting the Rhan function to equation 4 yields a temporal DF equation as shown in equation 5.

$$
D F(t)=\frac{1}{1-\left(1-\frac{1}{D F_{\text {equilibriu m }}}\right) \times\left[1-e^{-k \times t^{n}}\right]}
$$

The current strategy is to compute the equilibrium DF using equation 3 given an initial sorbate concentration and MST concentration or the MST concentrations given an initial sorbate concentration. Then the temporal changes of DF are computed using equation 4 (or 5 for example). A diagram of the calculation steps required for predicting DF as a function time is shown in Figure 1. 
When loading is controlled by both diffusion and adsorption, a non-analytical solution (by numerical integration) can be obtained. Only in the case of flux-controlled loading at the surface of MST, an analytical solution can be obtained as shown below.

$$
\begin{aligned}
& \frac{d q}{d t}=D \frac{\partial C}{\partial X} \text { at the surface. } \frac{\partial C}{\partial X}=\frac{C_{\text {bulk }}}{\sqrt{\pi D t}} \text { for semi-infinite plane diffusion } \\
& q=\frac{2 D^{1 / 2} C_{b u l k}}{\pi^{1 / 2}} t^{1 / 2}
\end{aligned}
$$

In this expression, $D$ stands for diffusivity, $C_{b}$ stands for the bulk concentration of the sorbate in solution and $t$ stands for time.

Researchers felt the lists of function listed Table 1 were sufficient to fit the data without the need for using rigorous numerical solutions to the coupled diffusion-adsorption kinetic equation. Table 1 present a set functions that covers both diffusion-limited sorption (both in solution and in the MST) and reaction controlled sorption (for example $1^{\text {st }}$ and $2^{\text {nd }}$ order reactions). Please note that successfully fitting sorption data with an exponential function does not necessarily implies first order rate sorption. Mathematical analysis of a sorption test carried under the conditions of a boundary layer around the sorbent also predicts an exponential function.

Researchers also evaluated the correlation coefficient $\left(\mathrm{r}^{2}\right)$ and standard error (SE) were computed to show the goodness of the fit. The $\mathrm{r}^{2}$ and SE definitions follow. 
$R^{2}=\frac{\sum(\text { Experiment value }- \text { Model prediction })^{2}}{\sum(\text { Experiment value }- \text { Mean of experiment values })^{2}}$

$S E=\sqrt{\frac{\sum(\text { Experiment value }- \text { Model prediction })^{2}}{\# \text { of data points }-\# \text { of parameters in the model }}}$

\subsection{Results}

Recalculation of the Equilibrium Dubinin-Astashov Parameters and Adsorption Enthalpy Researchers added the more recent data on strontium and actinide sorption with the previous dataset and re-calculated new DA parameters as described in the Experimental section. The DA expressions for $\mathrm{Sr}, \mathrm{Pu}, \mathrm{U}$ and $\mathrm{Np}$ are shown in equations $9-12$, respectively. All sorbate concentrations are shown in units of micromoles per liter $(\mu \mathrm{M})$ and loadings of sorbates onto MST in units of micromoles per gram of MST $(\mu \mathrm{mole} / \mathrm{g})$. Equations 9-12 represent the best DA function fit to a database that contains 3 different temperatures $\left(25^{\circ} \mathrm{C}, 45^{\bullet} \mathrm{C}\right.$ and $\left.65^{\circ} \mathrm{C}\right)$. This is a typical temperature range in the actinide removal process. Figures 2, 3, 4, and 5, show the Strontium, Uranium, Plutonium, and Neptunium loading on MST. Figures 2 through 5 also show the predictions from the DA function and the degree of fitting as determined from the square of the correlation coefficient. An inspection of Figure 2 through 5 reveals that Uranium (Figure 2), Plutonium (Figure 3), Strontium (Figure 4) and Neptunium (Figure 5) loading data shows a large increase in loading after an initial plateau is reached. The large loading increase may be an indication of multilayer formation. Since Uranium, Plutonium, and 
Neptunium extensively load on MST, they do not compete for the same sorption sites on MST. In a previous report, the Strontium and actinide sorption energy was measured. From the sorption energy, it was concluded that only Uranium and Neptunium formed multilayers on MST (for example Uranium precipitating or sorbing on an Uranium rich surface). The additional data point in Figure 3 is new evidence that Plutonium forms multilayer on MST.

$\underline{\text { Strontium }}$

Loaded $\operatorname{Sr}_{\text {equilibrium }}=27.4 \pm 4 \times e^{-0.2 \pm 0.03 \times\left(\operatorname{Ln} \frac{0.8 \pm 0.01}{[\mathrm{Sr}]}\right)^{3.6 \pm 0.3}}$

\section{$\underline{\text { Plutonium }}$}

Loaded Pu $_{\text {equilibrium }}=2.32 \pm 0.4 E 7 e^{-14.6 \pm 0.4 \times\left[\operatorname{Ln} \frac{0.68 \pm 0.04}{[P u]}\right]^{0.11 \pm 0.02}}$

\section{$\underline{\text { Uranium }}$}

Loaded $U_{\text {equilibrium }}=6 E 4 \pm 3 E 3 \times e^{-7.6 \pm 1.9\left(\operatorname{Ln} \frac{66 \pm 7}{[U]}\right)^{0.1 \pm 0.06}}$ 
$\operatorname{Loaded~} N p_{\text {equilibrium }}=1473 \pm 223 e^{-0.6 \pm 0.1\left[\operatorname{Ln} \frac{98 \pm 8}{[N p]}\right]^{0.1 \pm 0.02}}$

Model Discrimination between the Kinetic Functions

Discrimination analysis focused on the Sum of Square Errors for Strontium and radionuclides. Table 3 lists the resulting SSE values from fitting each function to the loading data of each actinide. We prefer that a single kinetic function provides a good fit for all four sorbates. Visual inspection of Table 3 revealed that the $1^{\text {st }}$ order, $2^{\text {nd }}$ order and Diffusion-limited models exhibited large residual errors. The Rudzinski model wasn't further considered because of the large number of mathematical operations and sensitivity to changes in the coefficient variations. Although both the Elovich and Power function fitted the uranium data best, loading with these functions are never expected to reach steady state. Recall one function contains an exponent and the other a power of 10 . The Sr loading data always reached steady state under several different initial conditions ruling out the Elovich and Power functions for fitting. Therefore, we excluded the Elovich and Power kinetic functions for further consideration.

The remaining models two models, Rhan and Ritchie, had similar fitting performance. We also considered the behavior of the rate constants derived from both of these models 
with varying MST concentration and initial sorbate concentrations. We observed that the initial rate of sorbate loading $(d q / d t)$ was the same under various different conditions (different initial actinide and strontium concentrations) as shown in Figures 6 to 9. This is evidence that the sorption process is reaction control instead of diffusion control. Since the rate of loading appears not to be a function of the final equilibrium loading, the expression in equation 13 indicates that the rate constant should decrease with increasing equilibrium loading.

$\frac{d q}{d t}=k(\downarrow)\left(q_{\text {equilibrium }}(\uparrow)-q(t)\right) \quad$ if $q_{\text {equilibri um }}$ increases, $k$ should decrease 13

Decreasing the MST concentration or increasing the sorbate concentration should decrease the rate constant. However, the rate constant should not change with loading capacity since it is a constant. Therefore, the data reflects the rate of loading was controlled by diffusion to the MST (transport limited). Since both functions (Rhan and Ritchie) fitted the loading data on MST, we chose the Rhan function for fitting this data since this function includes transport rate limited adsorption. It was also observed that the $\mathrm{Pu}$ rate constant data as a function of the steady state $\mathrm{Pu}$ loading on MST shown in Figures 10 (Rahn and Ritchie) revealed a significant noise (including bifurcation behavior) with the Ritchie's rate constant values, but not with the rate constant derived from the Rahn fitting function. Therefore, we selected the Rahn function to describe sorption on MST. 


$$
q_{P u}(t)=\text { Loaded } P u_{\text {equilibrium }} \times\left[1-e^{-k \times t^{n}}\right]
$$

In this expression, $q_{P u}(t)$ is the amount of plutonium loaded on MST (in units of micromole per grams of MST). The expression "Loaded Puequilibrium" is the equilibrium amount of plutonium on MST. The two parameters " $k$ " and " $n$ " were fitted against "Loaded $P u_{\text {equilibrium" parameter. }}$

A sample of the fitting performance of the Rahn function is shown in the Figure 11. A visual inspection of the figures in Figure 11 shows the good fit between the Rahn function and the radionuclide sorption data on MST. From this fitting, the rate constant and another parameter associated with the Rahn function were derived. We also computed the sensitivity of these two (rate constant and exponent value) parameters derived from the Rahn function. The sensitivity of the Rhan function to variations of its parameters is shown in Figure 12. The figures show the values of the parameters that minimized the Sum of Square Errors (SSE). The figures clearly that values for the rate constant and the exponent away from the minimum will not vary the SSE values significantly.

In order to predict sorption kinetics, we need to correlate the two parameters from Rahn's function (rate constant and exponent value) to the MST capacity for a given radionuclide. We fitted the Rhan's rate constant as an inverse function of the equilibrium loading for all nuclide. The resulting fitting curves for Uranium and Plutonium is shown in Figure 13. An inspection of Figure 13 showed a good fit between both parameters from the Rhan function and the ultimately $\mathrm{Pu}$ and $\mathrm{U}$ loading. Similar fitting performance was 
obtained by fitting the Strontium and Neptunium loading data. The inverse relationship between the Rhan's parameter and the steady state loading is consistent with the expectation that the farther the system is away from equilibrium the faster the system approach equilibrium initially. The fitted function provides the information needed to predict sorbate loading. The final loading functions for all sorbates follows.

\section{Plutonium}

$k=\frac{0.207 \pm 0.4}{\text { Loaded } P u_{\text {equilibriun }}}+0.01 \pm 0.002$
$n=\frac{1.71 \pm 0.8}{\text { Loaded } P u_{\text {equilibriun }}}+0.01 \pm 0.006$

\section{Strontium}

$$
\begin{aligned}
& k=\frac{-0.086 \pm 0.06}{\text { Loaded } S r_{\text {equilibriun }}}+4 \pm 0.6 \\
& n=\frac{0.7 \pm 0.02}{\text { Loaded } S r_{\text {equilibriun }}}+0.36 \pm 0.13
\end{aligned}
$$

Uranium

$$
\begin{aligned}
& k=\frac{1 \pm 0.34}{\text { Loaded } U_{\text {equilibrium }}}+0.16 \pm 0.1 \\
& n=\frac{0.7 \pm 0.4}{\text { Loaded }_{\text {equilibrium }}}+0.36 \pm 0.07
\end{aligned}
$$




\section{Neptunium}

$$
\begin{aligned}
& k=\frac{2.1 \pm 0.4}{\text { Loaded } N p_{\text {equilibriun }}}+0.11 \pm 0.12 \\
& n=\frac{-0.26 \pm 0.1}{\text { Loaded } N p_{\text {equilibriun }}}+0.55 \pm 0.3
\end{aligned}
$$

\section{$\underline{\text { Temperature Effect }}$}

We fitted the temporal sorption data at different temperatures. We expect the rate constant to follow the Arhenius law as a function of temperature as shown in Equation 23. Plotting the log of the rate constant (in the case of the Rhan function the constant is " $k$ ") as a function of the inverse of temperature should yield a linear trend. We found no statistical relationship between the other Rhan's parameter " $n$ " and the inverse of temperature. The slope of the line gives the enthalpy energy for radionuclide sorption on MST. The intercept (at large temperature) yields the rate constant at room temperature. Figures 14 provide plots of the rate constants as a function of temperature for $\mathrm{Pu}$ and $\mathrm{U}$, respectively.

The slope of the lines in Figure 14 yielded the activation energy for sorption. The activation energies measured $60 \mathrm{~kJ} / \mathrm{mol}$ for $\mathrm{Pu}$ and $6.5 \mathrm{~kJ} / \mathrm{mol}$ for $\mathrm{U}$. 
$k=k_{\text {room temperature }} e^{-\frac{\Delta E}{R T}}$

23

\section{$\underline{\text { Model Validation }}$}

We calculated the radionuclide sorption on MST at a concentration of $0.4 \mathrm{~g} / \mathrm{L}$ and at $25 \bullet \mathrm{C}$. The starting radionuclide concentrations and conditions for this prediction were identical to the experimental data obtained in previous report (13). Please note the data set in that report was not considered during the formulation of the current isotherm model. A comparison of plutonium and uranium loading with predictions is shown in Figures 15.

An inspection of Figures 15 showed that the model under-predicts the plutonium and uranium sorption data. In the case of uranium, the data did not reach equilibrium in 30 hours of testing. Therefore, the precision of the model's predictions cannot be fully ascertained. 


\section{Conclusions}

The Dubinin-Astashov (DA) isotherm parameters for $\mathrm{U}, \mathrm{Pu}, \mathrm{Sr}$ and $\mathrm{Np}$ have been updated to include additional data obtained since the original derivation. The DA isotherms were modified to include a kinetic function derived by Rahn to describe sorbate loading from the beginning of sorption up to steady state. The final functions describe both kinetic and thermodynamic sorption. 


\section{References:}

1-F. F. Fondeur, D. T. Hobbs, M. J. Barnes and S. D. Fink, “ Sorption Modeling of Sr, Pu, U and Np adsorption on Monosodium Titanate," WSRC-TR-2003-00180, May 2003.

2-Poirier, M. R., Herman, D. T., Burkett, P. R., Peters, T. B., Serkiz, S. M., and Fink, S. D., “Testing of the Insitu Mixed-Iron Oxide (ISMIO) Alpha Removal Process," WSRCTR-2004-00283, June 29, 2004.

3-Barnes, M. J., F. F. Fondeur, D. T. Hobbs, and S. D. Fink, "Monosodium Titanate Multi-Strike Testing,” WSRC-TR-2004-00145, April 29, 2004.

4-Azizian, S., "Kinetics Models of Sorption: a Theoretical Analysis," J. Coll. and Int. Sc., 2004, 276, pp. 47-52.

5- M. M. Dubinin and L. V. Radushkevich, "Equation of the Characteristic Curve of Activated Charcoal," Chem. Zentr Vol. 1(1947), p. 875.

6A-Cheung, C. W., Porter, J. F., and McKay, G., "Sorption Kinetic Analysis for the Removal of Cadmium Ions from Effluents Using Bone Char,' Wat. Res., 2001, 35, pp. 605-612.

6B- G.F. Forment and K. B. Bischoff, "Chemical Reactor Analysis and Design,” John wiley \& Sons, Inc. 1990.

7 -Rudzinski, W. and Panczyk, T, "Kinetics of Isothermal Adsorption on Energetically Heterogeneous Solid Surfaces: A New Theoretical Description Based on the Statistical Rate Theory of Interfacial Transport,” J. Phys. Chem. B, 2000, 104, pp. 9149-9162.

8 -Georgiadis, R., Peterlinz, K. P., and Peterson, A. W., “Quantitative Measurements and Modeling of Kinetics in Nucleic Acid Monolayer Films Using SPR Spectroscopy," J. Am. Chem. Soc., 2000, 122, pp. 3166-3173. 
9 -Sag, Y. and Aktay, Y, “Kinetic Studies on Sorption of $\mathrm{Cr}(\mathrm{VI})$ and $\mathrm{Cu}(\mathrm{II})$ ions by

Chitin, Chitosan, and Rhizopus arrhizus,” Biochemical Eng. J.,2002, 12, pp. 143-153.

10- Lazaridis, N. K., and Asouhidou, D. D., "Kinetics of Sorptive Removal of Chromium(VI) from Aqueous Solution by Clacined Mg-Al-CO3 hydrotalcite," Water Research, 2003, 37, pp. 2875-2882.

11 -Hibbert, D. B., Gooding, J. J., and Erokhin, P., "Kinetics of Irreversible Adsorption with Diffusion: Application to Biomolecule Immobilization," Langmuir, 2002, 18, pp. $1770-1776$.

12 -Barlow, K, Nash, D., Grayson, R, "Investigating Phosphorus Interactions with Bed Sediments in a Fluvial Environment using a Recirculating Flume and Intact Soil Cores," Water Research, 2004, 38, pp. 3420-3430.

13-“Demonstration of MST Efficacy on Removal of Actinides and Strontium in Bounding Alpha Waste," S. D. Fink, D. T. Hobbs and T. B. Peters, WSRC-TR-200200555, December 2002 


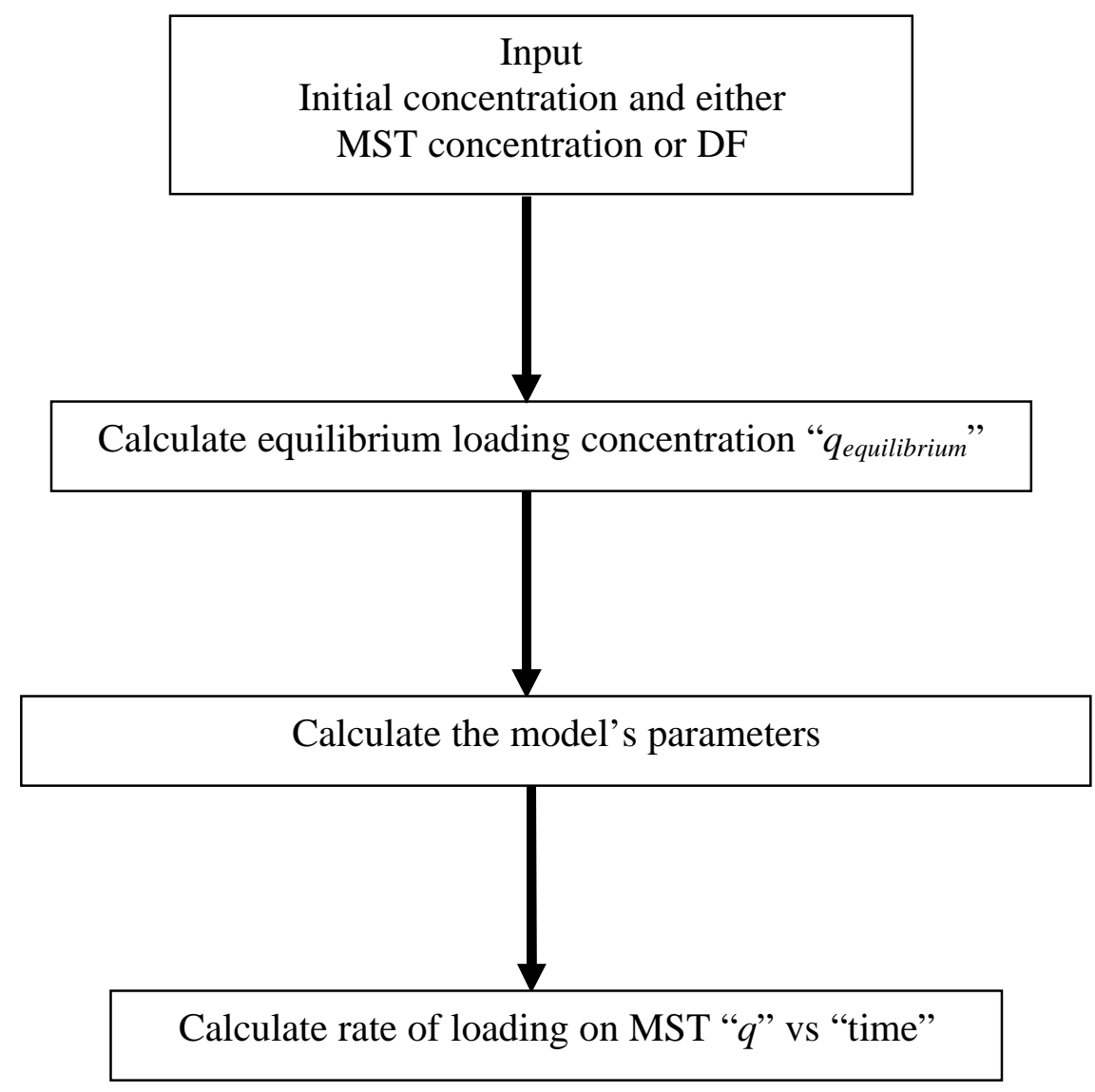




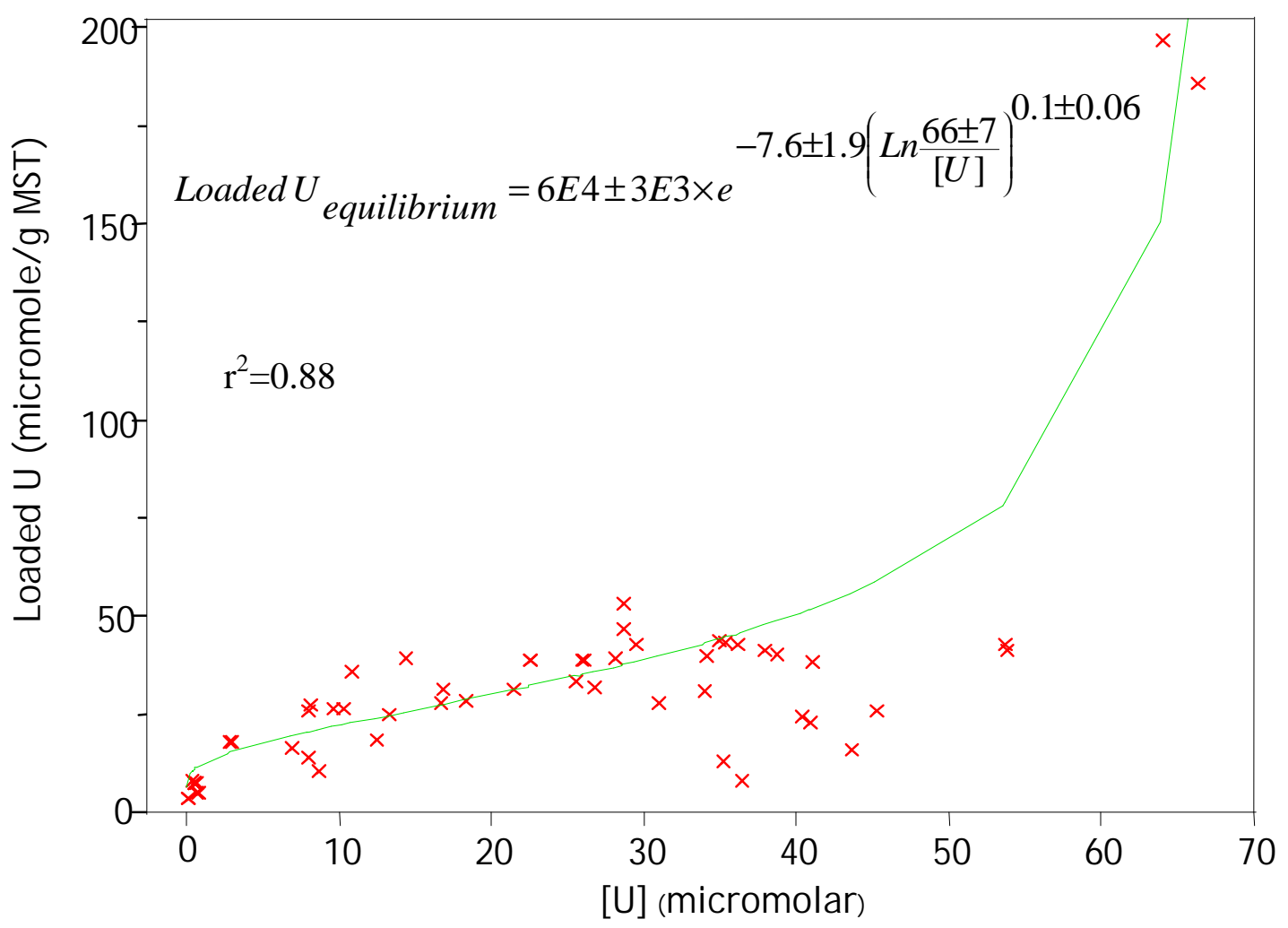




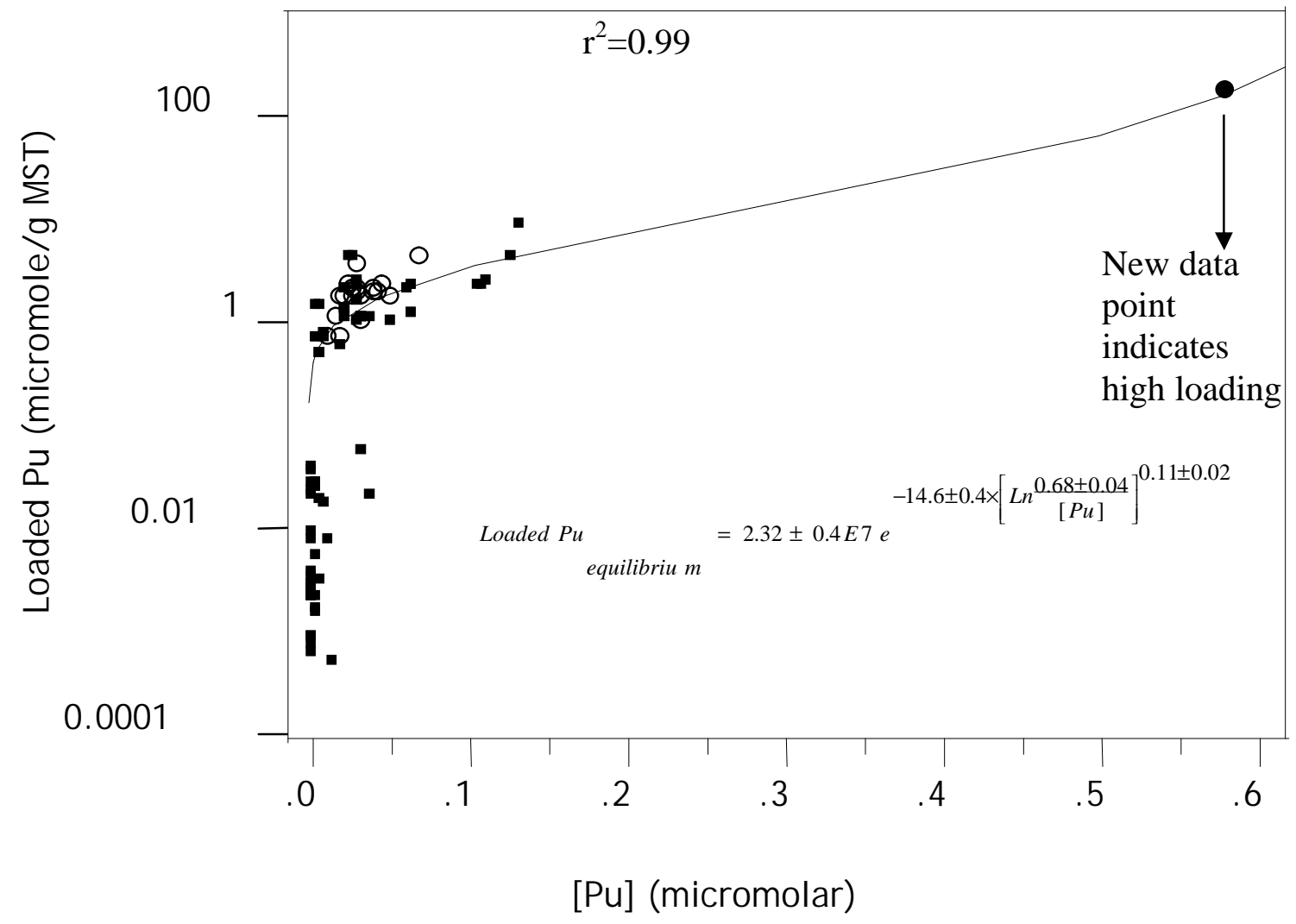




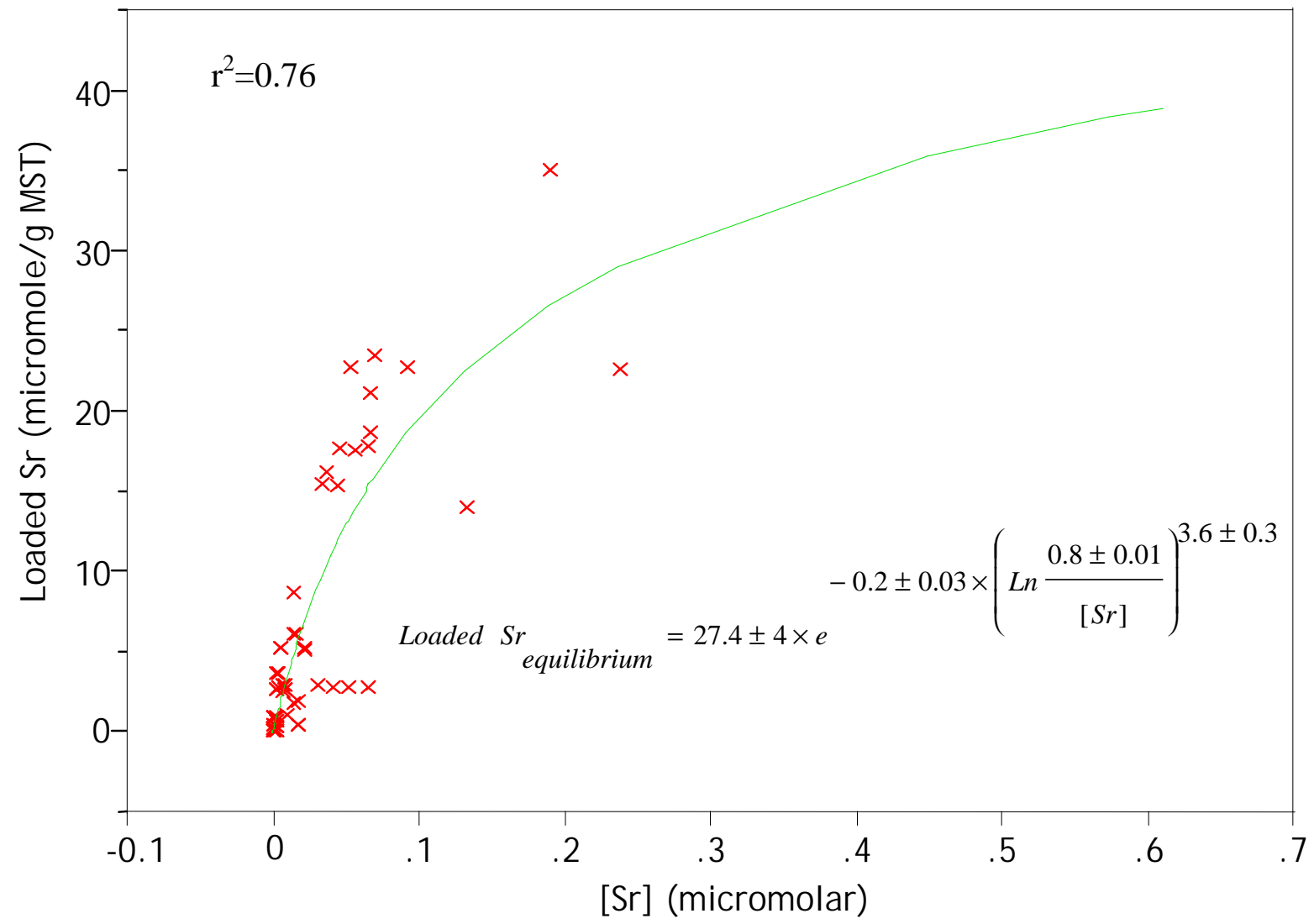




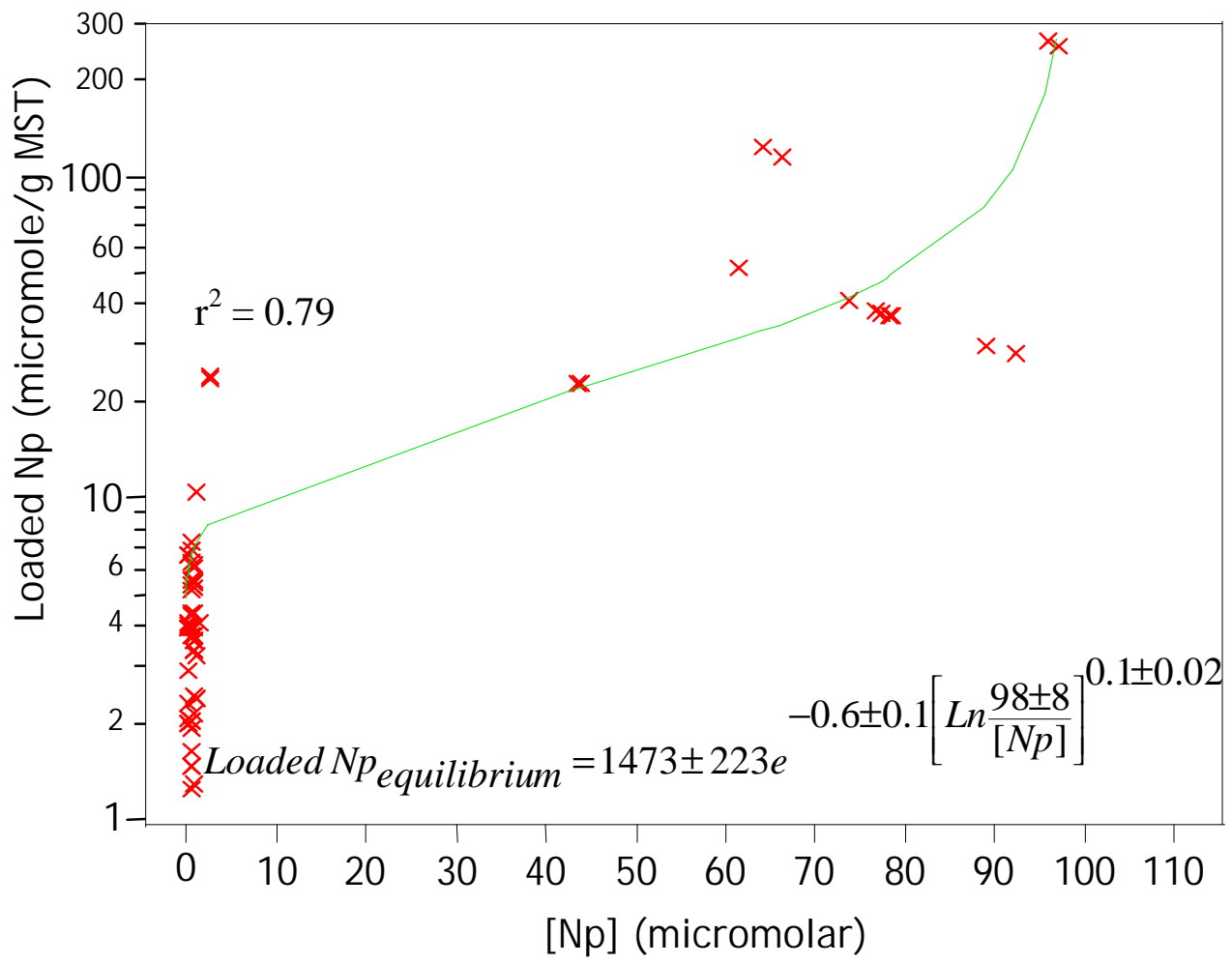




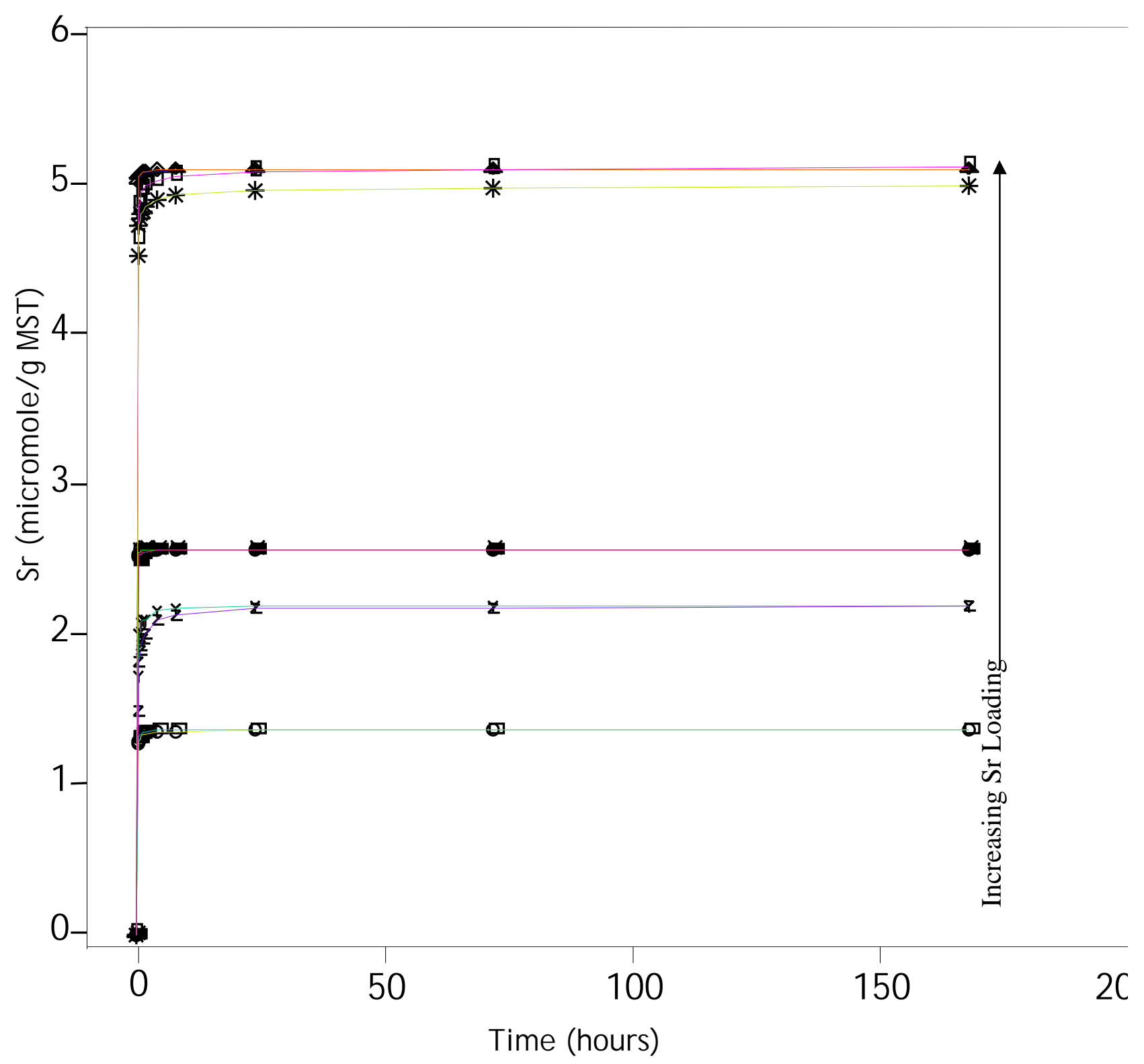




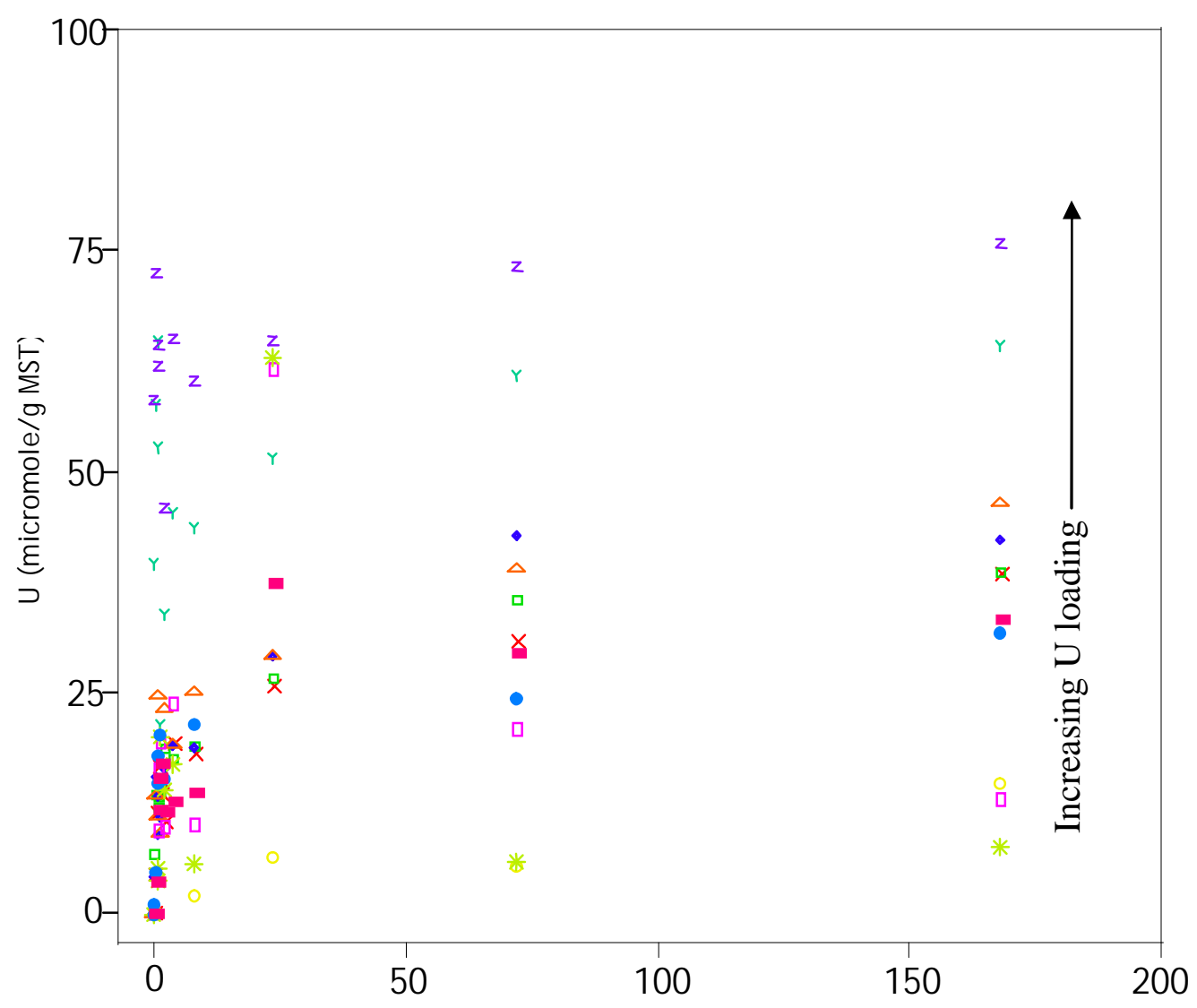




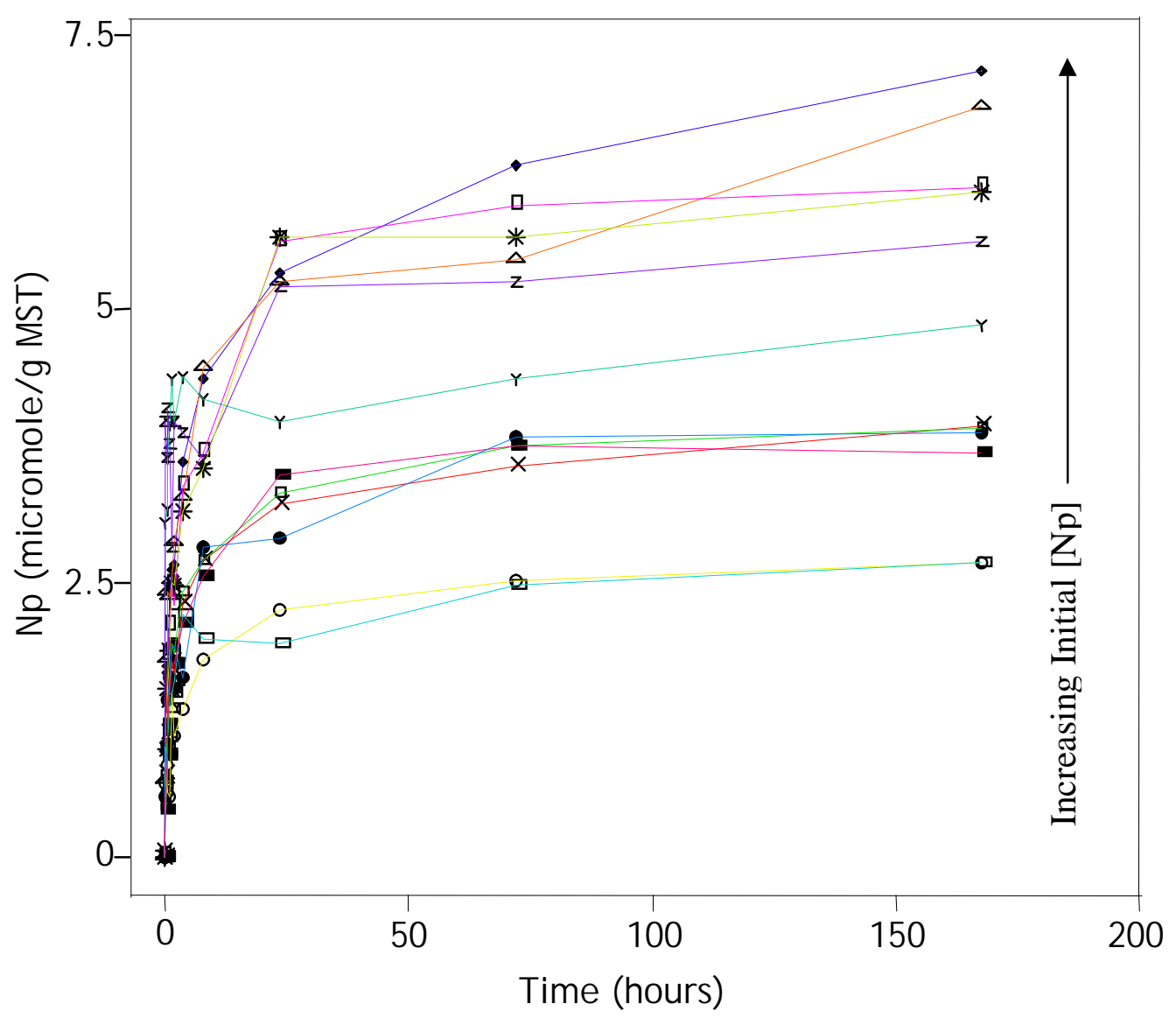



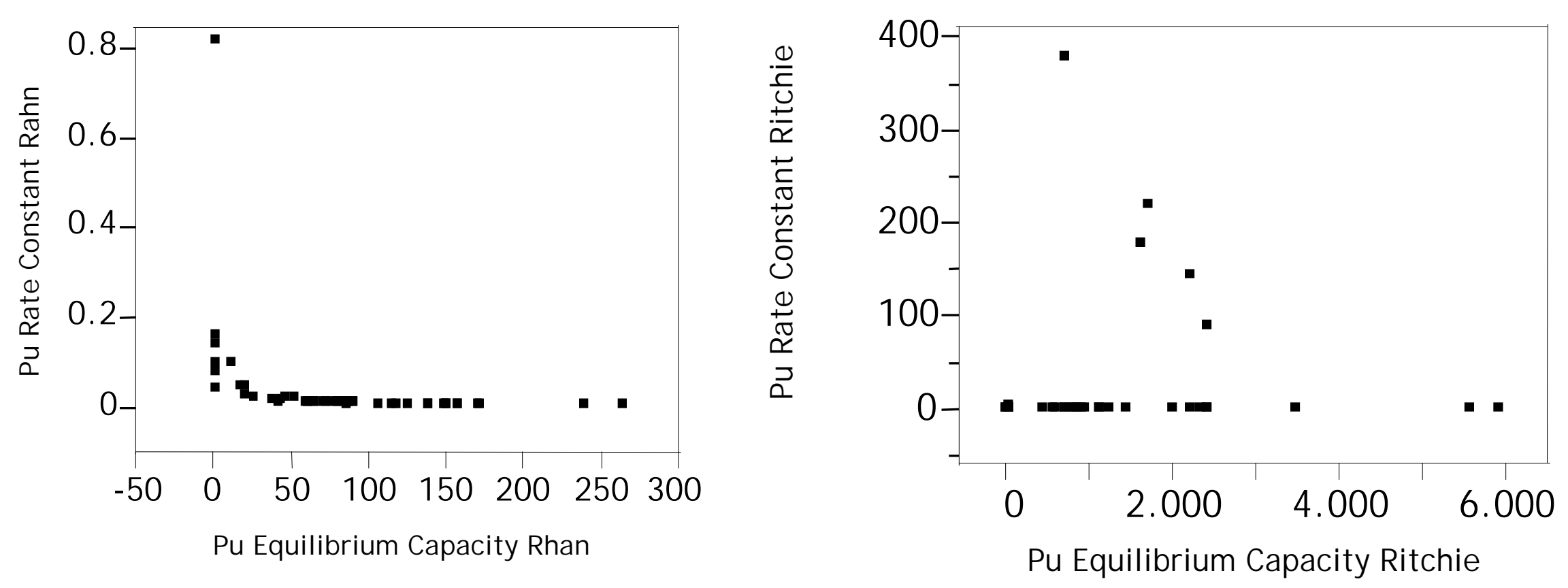

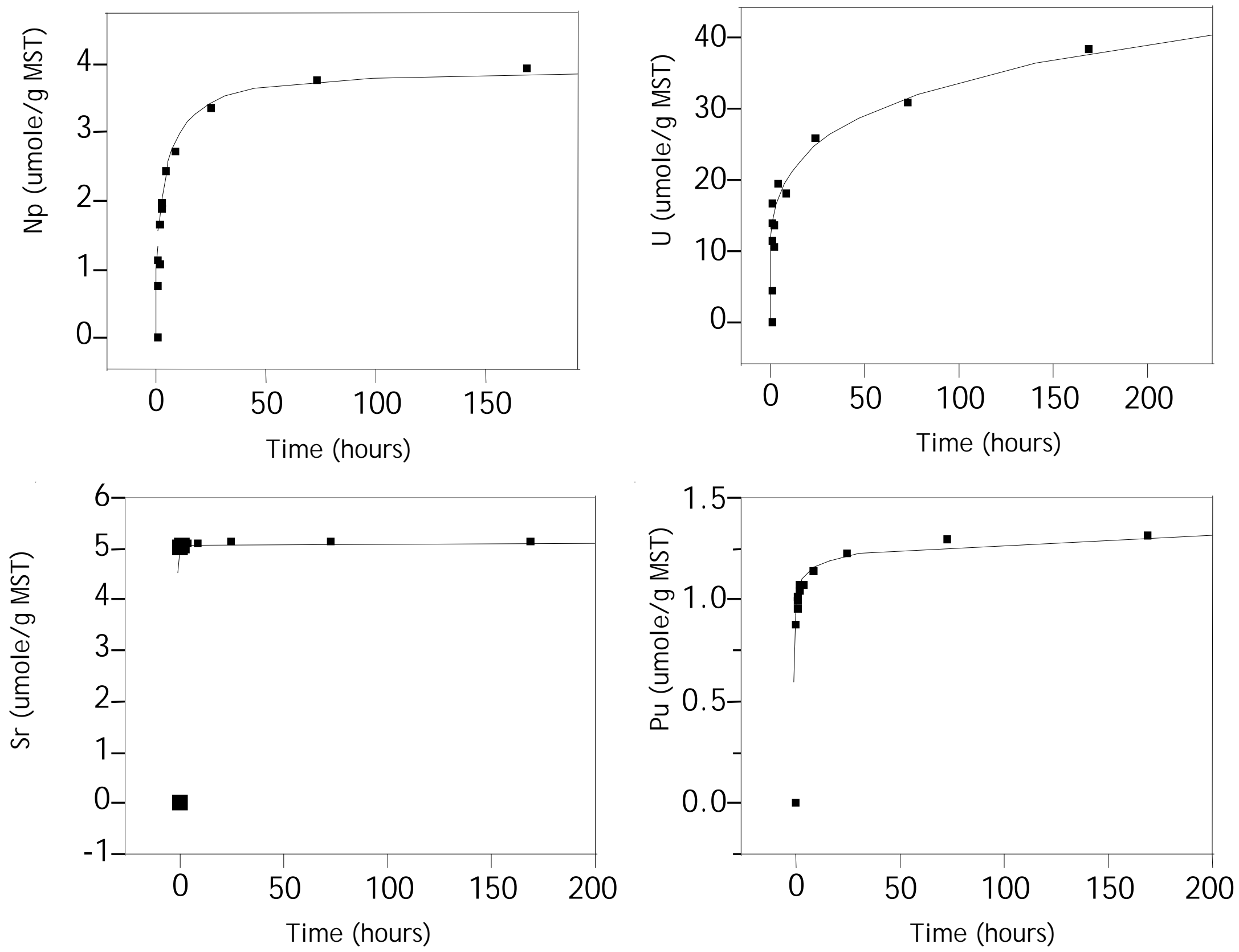

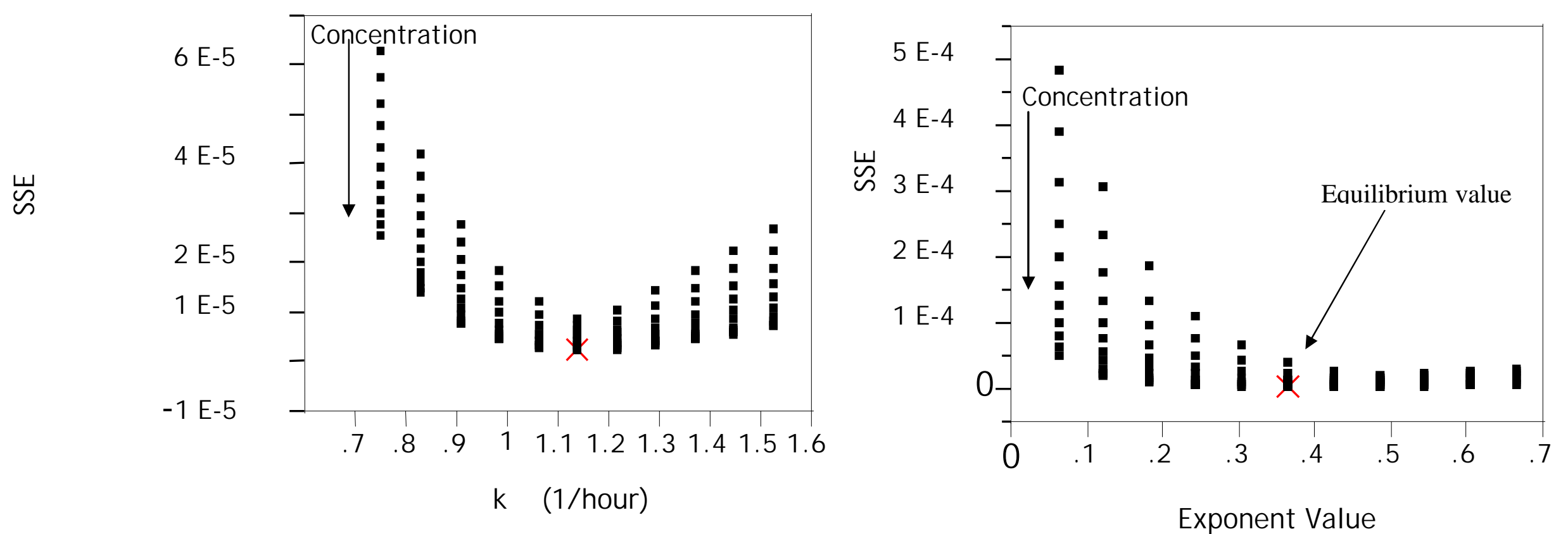

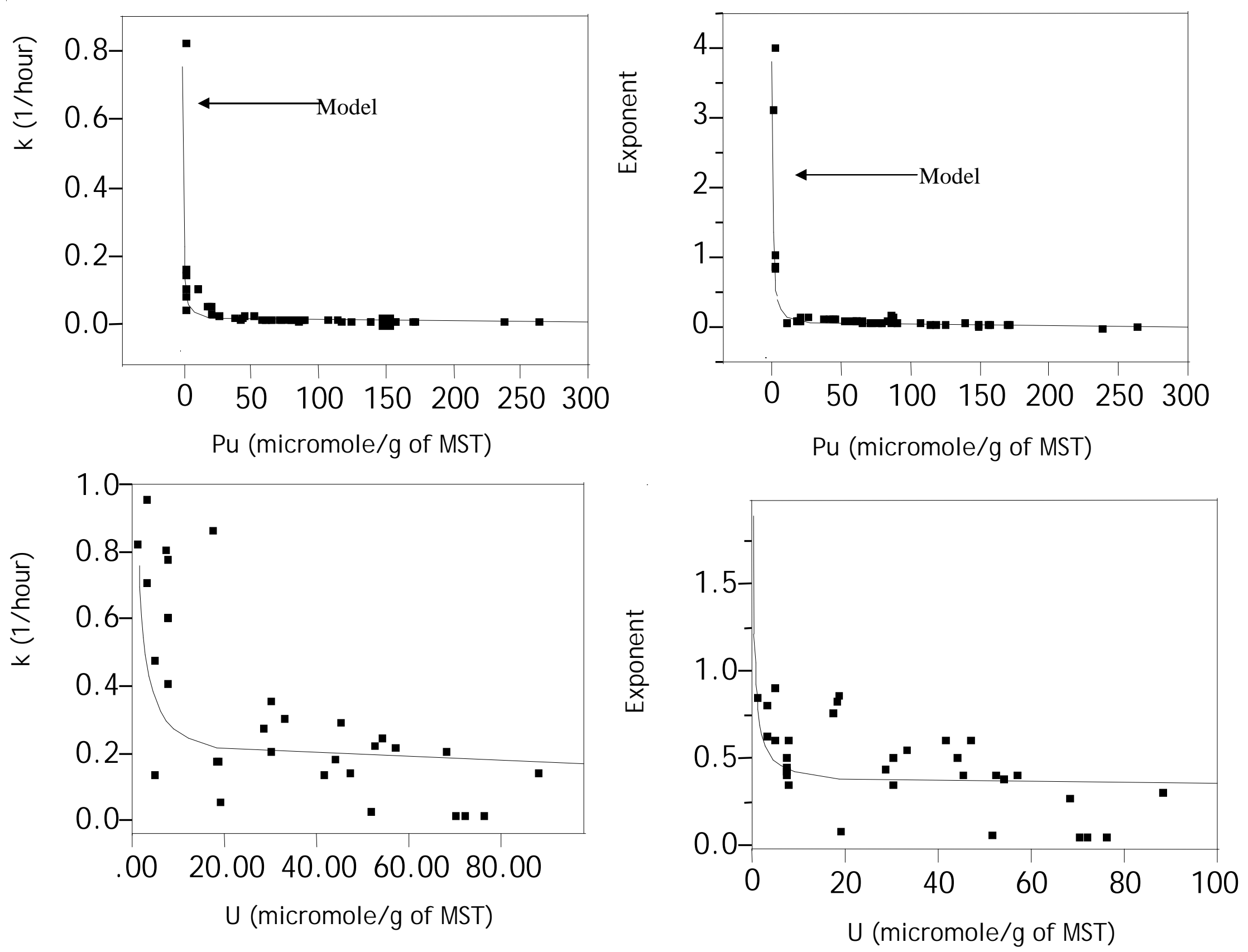

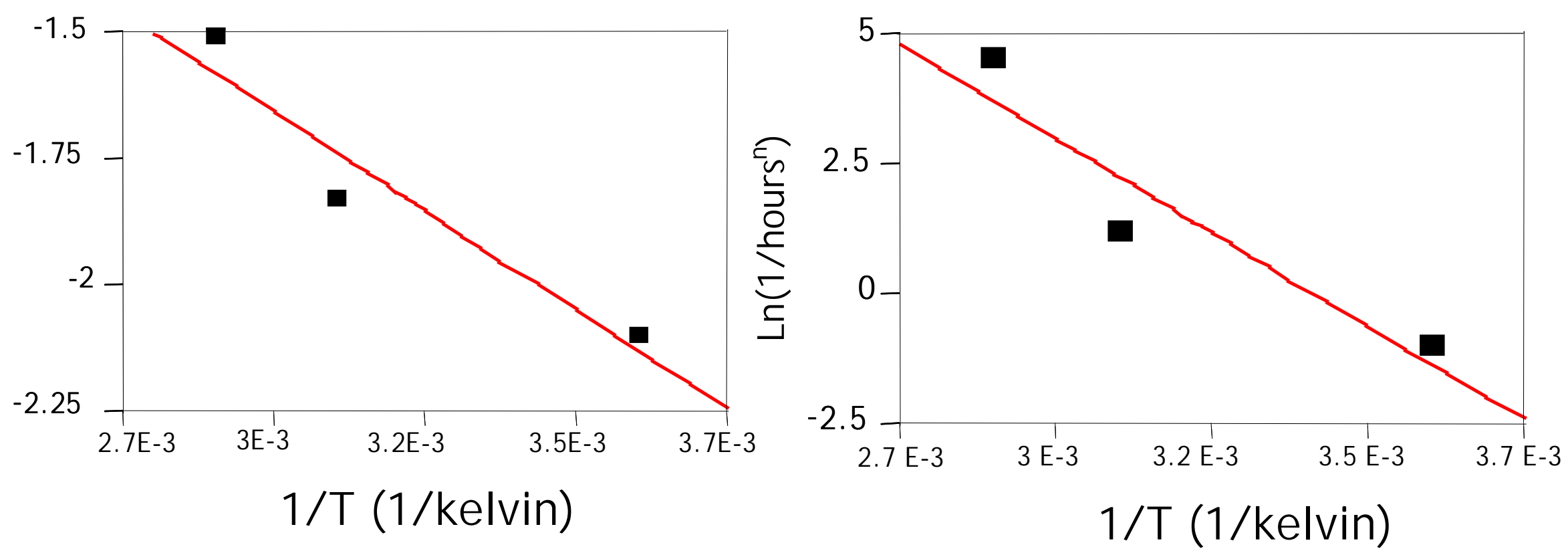

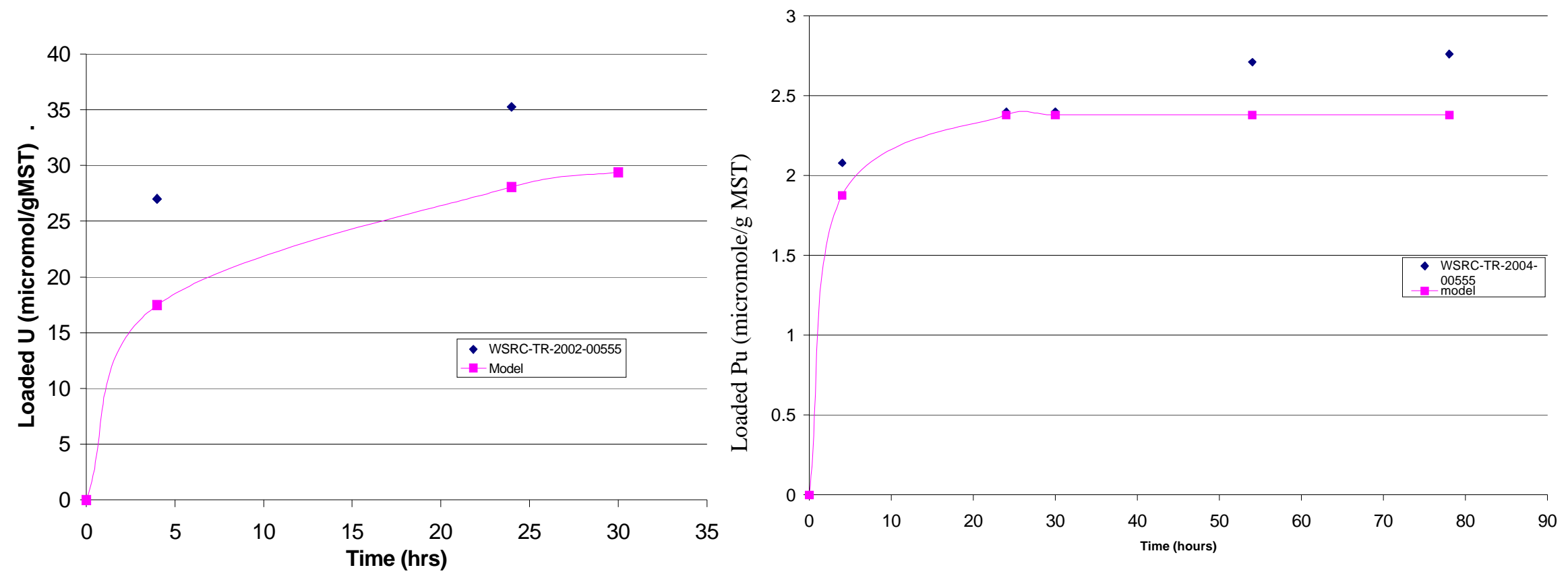
Table 1. The kinetic functions considered for fitting actinide loading.

\begin{tabular}{|c|c|c|c|c|}
\hline Model & Parameters & $\begin{array}{l}\text { \# } \\
\text { Mathematical } \\
\text { Operations of } \\
\text { operations }\end{array}$ & Formula & Reference \\
\hline First order & 2 & 5 & $q=q_{\text {equilibrium }}\left(1-e^{-k t}\right)$ & $6 \mathrm{~A}$ \\
\hline $\begin{array}{l}\text { Second } \\
\text { order }\end{array}$ & 2 & 5 & $\begin{array}{c}q=q_{\text {equilibrium }}(1- \\
1 /(1+k t))\end{array}$ & $6 \mathrm{~B}$ \\
\hline Ritchie & 3 & 6 & $\begin{array}{c}q=q_{\text {equilibrium }}(1- \\
\left.(1 /(1+k t))^{n}\right)\end{array}$ & 5 \\
\hline Elovich & 2 & 4 & $q=q_{\text {equilibrium }} \operatorname{Ln}(a t+1)$ & 7 \\
\hline $\begin{array}{l}\text { Diffusion } \\
\text { Limited }\end{array}$ & 1 & 2 & $q=b t^{1 / 2}$ & $8,9,11$, and 12 \\
\hline Power & 2 & 2 & $q=b t^{a}$ & 6 \\
\hline Rahn & 3 & 6 & $q=q_{\text {equilibrium }}\left(1-\exp \left(-k t^{n}\right)\right)$ & 4,10 \\
\hline $\begin{array}{c}\text { Shrinking } \\
\text { Core Model }\end{array}$ & 3 & 6 & $t=a\left[1-b x^{2 / 3}+c x\right]$ & $6 \mathrm{~B}$ \\
\hline Rudzinski & 4 & 11 & $\begin{array}{c}q=q_{\text {equilibrium }}(a \times \\
\operatorname{Arctan}(b t))^{c} / \\
\left(1+(a \times \operatorname{Arctan}(b t))^{c}\right)\end{array}$ & 7 \\
\hline
\end{tabular}


Table 2. Rate of loading equations for the kinetic expressions*

\begin{tabular}{|c|c|c|}
\hline Model & $\begin{array}{l}\text { Kinetic } \\
\text { Expression for } \\
\text { rate of loading } \\
\mathrm{dq} / \mathrm{dt}\end{array}$ & Reference \\
\hline First Order & $\mathrm{k}\left(\mathrm{q}_{\mathrm{exp}}-\mathrm{q}\right)$ & $6 \mathrm{~A}$ \\
\hline Second Order & $\mathrm{k}\left(\mathrm{q}_{\mathrm{exp}}-\mathrm{q}\right)^{2}$ & $6 \mathrm{~B}$ \\
\hline Ritchie & $\mathrm{k}\left(\mathrm{q}_{\mathrm{exp}}-\mathrm{q}\right)^{\mathrm{n}}$ & 5 \\
\hline Elovich & $\exp (-b q)$ & 7 \\
\hline Rahn & $\mathrm{k}\left(\mathrm{q}_{\exp }-\mathrm{q}\right) / \mathrm{t}^{\bullet}$ & 4,10 \\
\hline $\begin{array}{c}\text { Shrinking Core } \\
\text { Model }\end{array}$ & $\mathrm{D}(\bullet \mathrm{C} / \bullet \mathrm{X})_{\mathrm{MST}}$ & $6 \mathrm{~B}$ \\
\hline Rudzinski & $\mathrm{k}\left(\mathrm{q}_{\exp }-\mathrm{q}\right)^{\bullet} / \mathrm{q}^{\bullet}$ & 7 \\
\hline Diffusion & $\mathrm{D}(\bullet \mathrm{C} / \bullet \mathrm{X})_{0}$ & $8,9,11$ and 12 \\
\hline \multicolumn{3}{|c|}{$\begin{array}{l}\text { * Power model is an empirical function for fitting } \\
\text { sorption data that did not originated from a kinetic }\end{array}$} \\
\hline
\end{tabular}


Table 3. Sum of Square Error (SSE) values for the kinetic models

\begin{tabular}{|c|c|c|c|c|c|c|c|c|c|c|c|}
\hline Actinide & $\begin{array}{l}\text { Initial concentration } \\
\qquad(\mu \mathrm{M})\end{array}$ & $\begin{array}{l}\text { MST } \\
(\mathrm{g} / \mathrm{L})\end{array}$ & $\begin{array}{c}1^{\text {st }} \\
\text { Order }\end{array}$ & $\begin{array}{c}2^{\text {nd }} \\
\text { Order }\end{array}$ & Elovich & Rhan & Ritchie & Power & $\begin{array}{l}\text { Shrinking } \\
\text { Core } \\
\text { Model }\end{array}$ & Diffusion & Rudzinski \\
\hline \multirow[t]{5}{*}{$\mathrm{Pu}$} & 0.0047 & 0.2 & 1.07 & 0.95 & 0.14 & 0.18 & 0.16 & 0.16 & 3.6 & 4.5 & 0.19 \\
\hline & 0.04 & 0.2 & 0.88 & 0.81 & 1.02 & 1.1 & .33 & .48 & 6.1 & 5.6 & .24 \\
\hline & 0.04 & 2 & 0.91 & 0.78 & 0.93 & 1.04 & .23 & 0.28 & 8.3 & 5.4 & .25 \\
\hline & 1.17 & 0.2 & 1.24 & 1.33 & 1.48 & 1.65 & .26 & 0.32 & 5.6 & 7.0 & .31 \\
\hline & 0.7 & 2 & 1.1 & 0.42 & 0.24 & .36 & .12 & 0.92 & 23.2 & - & .09 \\
\hline \multirow[t]{4}{*}{$\mathrm{U}$} & 103 & 0.2 & 239 & 323 & 12 & 14 & 85 & 243 & 503 & 1044 & 78 \\
\hline & 103 & 2 & 247 & 289 & 27 & 24 & 34 & 432 & 681 & - & 46 \\
\hline & 62 & 0.2 & 122 & 341 & 16 & 15 & 63 & 428 & 285 & - & 55 \\
\hline & 62 & 2 & 113 & 419 & 18 & 21 & 47 & 238 & 654 & - & 46 \\
\hline \multirow{8}{*}{$\mathrm{Sr}$} & 0.093 & 0.2 & 0.35 & 0.23 & 0.423 & .61 & .22 & .30 & 28 & - & .33 \\
\hline & 0.093 & 2 & 0.49 & 0.24 & 0.43 & .72 & .20 & .44 & 42 & - & .23 \\
\hline & 0.71 & 0.2 & 0.89 & 1.45 & 0.98 & .83 & 1.34 & .56 & 26 & - & 1.29 \\
\hline & 0.71 & 2 & 0.76 & 1.91 & 0.84 & .79 & 1.88 & .38 & 18 & - & 1.67 \\
\hline & 1.01 & 0.2 & 1.21 & 0.983 & 1.25 & 1.14 & .878 & 0.89 & 94 & - & .9 \\
\hline & 1.01 & 2 & 1.34 & 0.824 & 0.825 & .91 & .674 & 0.68 & 48 & - & .66 \\
\hline & 1.2 & 0.2 & 1.95 & 1.28 & 1.354 & 1.24 & 1.1 & 1.1 & 64 & - & .95 \\
\hline & 1.2 & 2 & 1.9 & 1.44 & 3.49 & 2.78 & 1.12 & 1.29 & 83 & - & 1.2 \\
\hline $\mathrm{Np}$ & 1.43 & 0.2 & 154 & 141 & 84 & 95 & 69 & 53 & 429 & 638 & 56 \\
\hline
\end{tabular}




\begin{tabular}{|l|c|c|c|c|c|c|c|c|c|c|c|}
\hline & 1.43 & 2 & 198 & 134 & 184 & 168 & 79 & 143 & 934 & - & 79 \\
\hline & 1.7 & 0.2 & 391 & 238 & 384 & 346 & 189 & 423 & 735 & - & 1787 \\
\hline & 1.7 & 2 & 320 & 482 & 138 & 147 & 328 & 1032 & 748 & - & 330 \\
\hline & 7.16 & 0.2 & 560 & 382 & 304 & 289 & 310 & 231 & 527 & - & 310 \\
\hline & 7.16 & 2 & 501 & 427 & 348 & 329 & 419 & 487 & 763 & - & 411 \\
\hline & 88.6 & 0.2 & 667 & 592 & 139 & 129 & 490 & 382 & 835 & - & 485 \\
\hline & 88.6 & 2 & 495 & 236 & 354 & 388 & 200 & 428 & 934 & - & 198 \\
\hline & 148 & 0.2 & 799 & 209 & 323 & 379 & 189 & 389 & 743 & - & 188 \\
\hline & 148 & 2 & 813 & 1043 & 248 & 289 & 940 & 284 & 783 & - & 946 \\
\hline
\end{tabular}

